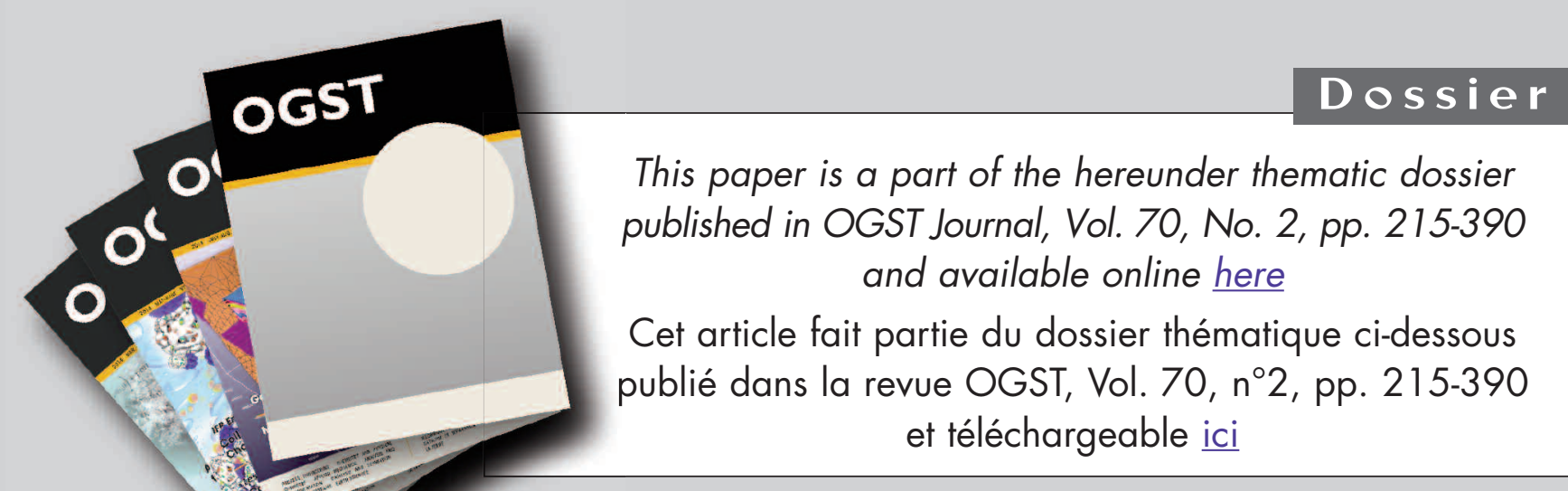

DOSSIER Edited by/Sous la direction de : B. Dewimille

Fluids-Polymers Interactions: Permeability, Durability

Interactions fluides polymères : perméabilité, durabilité

Oil \& Gas Science and Technology - Rev. IFP Energies nouvelles, Vol. 70 (2015), No. 2, pp. 215-390

Copyright (C) 2015, IFP Energies nouvelles

$215>$ Tribute to Yves Chauvin Hommage à Yves Chauvin

S. Candel and 0 . Appert

$219>$ Editorial

G. Kimmerlin

227 > Gas Permeation in Semicrystalline Polyethylene as Studied by Molecular Simulation and Elastic Model

Perméation de gaz dans le polyéthylène semi-cristallin par simulation moléculaire et modèle élastique

P. Memari, V. Lachet and B. Rousseau

237 > Reinforcement of the Gas Barrier Properties of Polyethylene and Polyamide Through the Nanocomposite Approach: Key Factors and Limitations

Renforcement des propriétés barrière aux gaz de matrices polyéthylène et polyamide par l'approche nanocomposite : facteurs clés et limitations E. Picard, J.-F. Gérard and É. Espuche

251 > Diffuso-Kinetics and Diffuso-Mechanics of Carbon Dioxide / Polyvinylidene Fluoride System under Explosive Gas Decompression: Identification of Key Diffuso-Elastic Couplings by Numerical and Experimental Confrontation

Cinétique de diffusion et comportement diffuso-mécanique du système dioxide de carbone / polyfluorure de vinylidène sous décompression explosive de gaz : identification des couplages diffuso-élastiques majeurs par confrontation numérique et expérimentale

J.-C. Grandidier, C. Baudet, S. A. E. Boyer, M.-H. Klopffer and L. Cangémi

267 > Characterization of Polymer Layered Silicate Nanocomposites by Rheology and Permeability Methods: Impact of the Interface Quality

Caractérisation de nanocomposites polymère silicate par des méthodes de rhéologie et de perméabilité : rôle de la qualité de l'interface

R. Waché, M.-H. Klopffer and S. Gonzalez

$279>$ Evaluation of Long Term Behaviour of Polymers for Offshore Oil and Gas Applications

Durabilité des polymères pour application pétrolière offshore

P.-Y. Le Gac, P. Davies and D. Choqueuse

$291>$ Development of Reactive Barrier Polymers against Corrosion for the Oil and Gas Industry: From Formulation to Qualification through the Development of Predictive Multiphysics Modeling

Développement de matériaux barrières réactifs contre la corrosion pour l'industrie pétrolière : de la formulation à la qualification industrielle en passant par le développement de modèles multiphysiques prédictifs

X. Lefebvre, D. Pasquier, S. Gonzalez, T. Epsztein, M. Chirat and F. Demanze
$305>$ Development of Innovating Materials for Distributing Mixtures of Hydrogen and Natural Gas. Study of the Barrier Properties and Durability of Polymer Pipes

Développement de nouveaux matériaux pour la distribution de mélanges de gaz naturel et d'hydrogène. Étude des propriétés barrière et de la durabilité de tubes polymères

M.-H. Klopffer, P. Berne and É. Espuche

317 > New Insights in Polymer-Biofuels Interaction

Avancées dans la compréhension des interactions polymères-biocarburants E. Richaud, F. Diouani, B. Fayolle, J. Verdu and B. Flaconneche

$335>$ Biofuels Barrier Properties of Polyamide 6 and High Density Polyethylene Propriétés barrière aux bio essences du polyamide 6 (PA6) et du polyéthylène haute densité (PEHD)

L.-A. Fillot, S. Ghiringhelli, C. Prebet and S. Rossi

353 > Permeability of EVOH Barrier Material used in Automotive Applications: Metrology Development for Model Fuel Mixtures

Perméabilité d'un matériau barrière EVOH utilisé dans des applications automobiles : développement métrologique pour des mélanges modèles de carburants

J. Zhao, C. Kanaan, R. Clément, B. Brulé, H. Lenda and A. Jonquières

367 > Effects of Thermal Treatment and Physical Aging on the Gas Transport Properties in Matrimid ${ }^{\circledR}$

Les effets du traitement thermique et du vieillissement physique sur les caractéristiques du transport au gaz dans le Matrimid ${ }^{\circledR}$

L. Ansaloni, M. Minelli, M. Giacinti Baschetti and G. C. Sarti

381 > Separation of Binary Mixtures of Propylene and Propane by Facilitated Transport through Silver Incorporated Poly(Ether-Block-Amide) Membranes Séparation de mélanges binaires de propylène et de propane par transport au travers des membranes de poly(éther-blocamide) incorporant de l'argent R. Surya Murali, K. Yamuna Rani, T. Sankarshana, A. F. Ismail and S. Sridhar 


\title{
Biofuels Barrier Properties of Polyamide 6 and High Density Polyethylene
}

\author{
L.-A. Fillot*, S. Ghiringhelli, C. Prebet and S. Rossi \\ LPMA (UMR 5268 CNRS/Solvay), Advanced Polymer Material Department, R\&I Centre Lyon, SOLVAY, 69192 Saint-Fons - France \\ e-mail: lovise-anne.fillot@solvay.com \\ * Corresponding author
}

\begin{abstract}
In this paper, a comparison of the biofuels barrier properties of PolyAmide 6 (PA6) and High Density PolyEthylene (HDPE) is presented. Model fuels were prepared as mixtures of toluene, isooctane and ethanol, the ethanol volume fraction varying between $0 \%$ and $100 \%$. Barrier properties were determined at $40^{\circ} \mathrm{C}$ by gravimetric techniques or gas chromatography measurements, and it was shown that polyamide 6 permeability is lower than that of polyethylene on a wide range of ethanol contents up to $85 \%$ of ethanol (E85) in the biofuel, permeability of PA6 being 100 times lower than that of HDPE for low ethanol content fuels (E5, E0). The time-lags were also compared, and on the whole range of ethanol contents, HDPE permeation kinetics appears to be much faster than that of $P A 6$, the time lag for a $1 \mathrm{~mm}$ thick specimens in presence of E10 being 50 days for PA6 and 0.5 days for HDPE. The compositions of the solvent fluxes were analyzed by FID (Flame Ionization Detector) gas chromatography, and it turned out that the solvent flux was mainly made up of ethanol (minimum 95\%) in the case of PA6, whereas in the case of HDPE, solvent flux was mainly made up of hydrocarbons. The implication of this difference in the solvent flux composition is discussed in the present article, and a side effect called the "fuel exhaustion process" is presented. The influence of the sample thickness was then studied, and for the different biofuels compositions, the pervaporation kinetics of polyamide 6 appeared to evolve with the square of the thickness, a long transitory regime being highlighted in the case of $P$ A6. This result implies that the time needed to characterize the steady state permeability of thick PA6 parts such as fuel tanks can be very long (one year or more), this duration being far superior to the Euros 5 or Euro 6 standard emission measurements time scale. The influence of temperature on the permeability was finally assessed, and the activation energy that is the signature of the temperature dependence of the barrier property turned out to be similar for the different biofuels compositions.
\end{abstract}

Résumé - Propriétés barrière aux bio essences du polyamide 6 (PA6) et du polyéthylène haute densité (PEHD) - Dans cet article, les propriétés barrière aux bio essences du PolyAmide 6 (PA6) sont comparées à celles du PolyEthylène Haute Densité (PEHD). Des essences modèles sont préparées en faisant varier entre 0 et $100 \%$ la fraction volumique d'éthanol dans des mélanges ternaires éthanol/toluène/isooctane. Les propriétés barrière aux bio essences sont caractérisées à $40{ }^{\circ} \mathrm{C}$ par gravimétrie ou par des mesures de chromatographie en phase gaz, et il est montré que la perméabilité du PA6 est plus faible que celle du PEHD sur une grande gamme de compositions d'essences contenant jusque $85 \%$ d'éthanol, le ratio de performance atteignant un facteur 100 pour les essences faiblement alcoolisées (E5, E0). Les temps d'induction ont aussi été comparés, et pour toutes les compositions d'essences évaluées, il apparait que la cinétique de pervaporation du PEHD est bien plus rapide que celle du PA6, le

This is an Open Access article distributed under the terms of the Creative Commons Attribution License (http://creativecommons.org/licenses/by/4.0), which permits unrestricted use, distribution, and reproduction in any medium, provided the original work is properly cited. 
temps d'induction pour un échantillon de $1 \mathrm{~mm}$ d'épaisseur en présence de E10 étant 50 jours dans le cas du PA6 contre 0,5 jour dans le cas du PEHD. La composition du flux de solvant a ensuite été analysée par chromatographie en phase gaz avec détecteur FID (Flame Ionization Detector), et il s'avère que le flux de solvant est dans le cas du PA6 très majoritairement composé d'éthanol (minimum $95 \%$ ), tandis que dans le cas du PEHD, le flux de solvant est composé majoritairement d'hydrocarbures. L'implication de cette différence de composition du flux de solvant est discutée dans le présent article, et un effet collatéral appelé processus d'appauvrissement de l'essence est présenté. L'influence de l'épaisseur de l'échantillon est ensuite étudiée, et pour toutes les compositions d'essence, il apparait que la cinétique de pervaporation du PA6 évolue avec le carré de l'épaisseur de l'échantillon, un long régime transitoire étant observé dans le cas du PA6. Ce résultat implique que le temps nécessaire pour caractériser la perméabilité en régime permanent de pièces massives en PA6 telles que des réservoirs d'essence peut être extrêmement long (une année ou plus), cette durée étant bien supérieure à l'échelle de temps associée aux mesures d'émissions réalisées dans le cadre de normes telles que Euro 5 ou Euro 6. L'influence de la température sur la perméabilité du PA6 est finalement étudiée, et il apparait que la valeur d'énergie d'activation qui traduit la dépendance de la perméabilité avec la température dépend peu du taux d'éthanol dans l'essence.

\section{INTRODUCTION}

In the last ten years, petrol price hike and environmental issues strongly encourage to reduce greenhouse gas emissions, an increasing interest being set on fuels derived from the biomass (biofuels), and notably fuels containing alcohol. In parallel, in order to lighten cars, metal is progressively replaced by plastic, but polymer parts such as fuel tanks must fulfill strict specifications in term of barrier properties. The emission standards are defined in a series of directives such as the Euro 5 (since 2009) or the Euro 6 (starting from 2014) directives in Europa, or American programs of the Californian Air Resources Board (CARB) such as the Partial Zero Emission Vehicles (PZEV). Evaporative emission permeation tests such as the SHED or the mini-SHED tests (Sealed Housing Evaporative Determination) are performed by manufacturers in order to evaluate and homologate the performance of fuel systems. In the SHED configuration, a whole vehicle which has rolled $3000 \mathrm{~km}$ and which contains a fuel tank filled at 40\% with E5 (5\% ethanol, 95\% gasoline) is placed in a chamber in which a specific temperature variation between $23^{\circ} \mathrm{C}$ and $31^{\circ} \mathrm{C}$ is applied during 24 hours. During this one day cycle, the total emissions are measured with a Flame Ionization Detector (FID), and in the case of Euro 6, this total emission should not exceed $2 \mathrm{~g}$ /day per vehicle, the fuel system being estimated to be responsible for around $80 \%$ of the observed evaporations [1].

The most commonly used polymer based solution for fuel systems was initially High Density PolyEthylene (HDPE), but as regulations became more and more drastic, a substantial improvement of the barrier properties of fuel systems was made by adding a fluorination post-treatment to HDPE, or by developing multilayer structures comprising a layer of a high barrier material such as Ethylene Vinyl Alcohol copolymer (EVOH) sandwiched between layers of polyethylene or polyethylene/polyamide blends. But the fluorination solution is not environmentally-friendly, and the co-extrusion of multilayers plastic fuel tanks requires specific and expensive processing equipment. As PolyAmide 6 (PA6) exhibits intrinsically a high barrier property to biofuels, its use in fuel tanks designed for a monolayer strategy is very relevant.

In this paper, the barrier properties of PA6 are compared to the barrier properties of HDPE in presence of fuel containing various ethanol contents. In the last 30 years, research and development of alcohol fuels has taken center stage as a way to reduce vehicle tailpipe emissions and the reliance to fossil fuels. And for the past several decades, a variety of automotive manufacturers have been designing and manufacturing vehicles to run on fuels made of $85 \%$ ethanol and $15 \%$ gasoline (E85), the fuel E10 (10\% ethanol, $90 \%$ gasoline) being the fuel commonly supplied in French gas stations. In contrast with polyethylene, polyamide is a polar polymer due to the presence of amide groups in its structure. A direct consequence of this polarity difference between polyamide and polyethylene is that polyamide is expected to present excellent barrier properties to non-polar solvents such as hydrocarbons, whereas polyethylene is expected to present excellent barrier properties to polar solvents such as ethanol or water. The behavior of these polymers 
in presence of hydrocarbons or some polar/apolar solvents mixtures [1-3], and the strategy to add polyamide in polyolefins to increase the barrier performance to hydrocarbons have been widely studied in the literature [4-12], but to our knowledge, few comparative studies of the behavior of these polymers in presence of toluene/ isooctane/ethanol ternary mixtures have been conducted.

As permeability of polymers to solvents depends on both solvent solubility and solvent diffusion kinetics, sorption experiments on PA6 and HDPE were conducted in this work in addition of pervaporation experiments. Gravimetric tests were used as well as FID gas chromatography analysis which allowed quantifying the different molecules present in the solvent flux. The obtained results were then discussed regarding the actual methodology and the expectations of the Euros 6 emission standards. Beyond the comparison of the biofuels barrier properties of PA6 and HDPE, the goal of this article is to shed some light on the environmental parameters that affects significantly the biofuels barrier properties of PA6 and HDPE (fuel composition, sample thickness, temperature) and to highlight the consequences of the differences observed between PA6 and HDPE.

\section{EXPERIMENTAL}

\subsection{Materials}

Polyamide 6 (PA6) was a commercial grade supplied by Solvay with a number average molecular weight determined by size exclusion chromatography of $27600 \mathrm{~g} / \mathrm{mol}$. HDPE was a commercial grade supplied by Polymeri Europa with a number average molecular weight determined by size exclusion chromatography of $21300 \mathrm{~g} / \mathrm{mol}$. It should be kept in mind that the polymers evaluated in this work were virgin PA6 or HDPE grades, and not formulations specifically developed for fuel systems.

\subsubsection{Injection Molded Plates}

Injection molded plates of PA6 and HDPE of dimensions $100 \times 100$ with a thickness of $0.8 \mathrm{~mm}$ were realized using a Demag injection molding machine exhibiting a clamping force of 80 tons. PA6 and HDPE were processed in similar processing conditions: the injection speed was $170 \mathrm{~mm} / \mathrm{s}$, the melt temperature was set at $270^{\circ} \mathrm{C}$ and the mold temperature at $80^{\circ} \mathrm{C}$. It should be pointed out that these processing conditions and namely the processing temperature are for HDPE a bit outside its conventional processing window, but the integrity of the HDPE polymer turned out to be little affected. Indeed, thermogravimetric analyses showed only a $2.5 \%$ weight loss after maintaining the polymer $30 \mathrm{~min}-$ utes at $290^{\circ} \mathrm{C}$, high temperature size exclusion chromatography measurements performed on HDPE before and after processing showed only minor changes on weight average molecular mass $(\mathrm{Mw}:-15 \%)$ and Polydispersity Index (PI: $+50 \%)$, and capillary rheometry measurements on HDPE before and after processing showed no significant viscosity change.

\subsubsection{Cast Extruded Films}

Extruded cast films of PA6 were realized using a co-rotating twin screw Leistritz extruder of diameter $34 \mathrm{~mm}$ and ratio length in diameter $L / D$ of 35 associated to a film set-up composed of a specific flat die of $300 \mathrm{~mm}$ width, followed by two chill-roll set at $125^{\circ} \mathrm{C}$, and series of rolls that finally allow to wind the film. The gap of the die and the speed of the rolls were changed in order to generate different film thicknesses of about 50, 125, 200, 500, and $800 \mu \mathrm{m}$. The extruder throughput was $7.8 \mathrm{~kg} / \mathrm{h}$, the melt temperature set at $255^{\circ} \mathrm{C}$, and the screw speed set at $250 \mathrm{rpm}$.

\subsection{Experimental Techniques}

\subsubsection{Characterization of Samples Crystallinity}

The crystallinity of polyamide 6 samples was characterized at several scales with Differential Scanning Calorimetry (DSC), Wide Angle X-ray Scattering (WAXS) and optical microscopy. HDPE was only characterized by DSC. The crystalline fraction was determined by DSC with a TA Q2000 calorimeter. Samples (between 7 and $15 \mathrm{mg}$ ) were put in non-hermetic aluminium pans and heated from $25^{\circ} \mathrm{C}$ to $300^{\circ} \mathrm{C}$ at a heating rate of $10^{\circ} \mathrm{C} / \mathrm{min}$. The crystalline fraction $\left(X_{c}\right.$ in $\left.\%_{\text {weight }}\right)$ was then determined from Equation (1):

$$
X_{c}=\left(\frac{\Delta H_{m}}{\Delta H_{m}^{100 \%}}\right) * 100
$$

where $\Delta H_{m}$ is the measured melting enthalpy, and $\Delta H_{m}^{100 \%}$ the reference melting enthalpy associated to a theoretical $100 \%$ crystalline polymer (taken as $191 \mathrm{~J} / \mathrm{g}$ for PA6 and $293 \mathrm{~J} / \mathrm{g}$ for HDPE [12]).

The crystalline structure of PA6 was characterized by WAXS at room temperature $\left(23^{\circ} \mathrm{C}\right)$, using a Brucker D8 Advance diffractometer. The source consisted in a ceramic tube with a copper anode generating $\mathrm{CuK} \alpha$ 
TABLE 1

Composition of the different solvent mixtures studied in this work (volumetric proportions)

\begin{tabular}{l|c|c|c|c|c|c|c|c}
\hline Mixture & E0 & E5 & E10 & E22 & E40 & E60 & E85 & E100 \\
\hline$\%$ ethanol (vol) & 0 & 5 & 10 & 22 & 40 & 60 & 85 & 100 \\
\hline$\%$ toluene (vol) & 50 & 47.5 & 45 & 39 & 30 & 20 & 7.5 & 0 \\
\hline$\%$ isooctane (vol) & 50 & 47.5 & 45 & 39 & 30 & 20 & 7.5 & 0 \\
\hline
\end{tabular}

radiation, and the measurements were performed in the reflection mode.

The spherulite structure in PA6 was characterized by polarized optical microscopy. Specimens were first included in epoxy resin and placed in an oven at $70^{\circ} \mathrm{C}$ overnight. From these prepared specimens, sections of $2 \mu \mathrm{m}$ thick were cut at room temperature by using a Reichert Ultracut $\mathrm{S}$ microtome equipped with a diamond knife. The sections were analyzed by using a Leica light polarization microscope equipped with video camera Leica DFC420C.

\subsubsection{Solvent Mixtures Preparation}

Commercial fuels were assimilated to ternary mixtures of ethanol, toluene and isooctane. These mixtures were prepared with different ethanol volume fractions, the list of the prepared mixtures and their composition being shown in Table 1. Analytical-grade solvents were used and ethanol was kept anhydrous with a desiccant.

\subsubsection{Solvent Sorption Assessment by Gravimetry}

Samples of dimensions $50 \times 50$ were cut in extruded films or in injection molded plates to study their solvent intake by gravimetry. Before immersion in the solvent, PA6 samples were dried overnight at $110^{\circ} \mathrm{C}$ under vacuum. The sorption device consisted in a crystallizing dish filled with the solvent or the solvent mixture and regulated in temperature thanks to a stir plate set at $40^{\circ} \mathrm{C}$. Samples were immerged in the solvent and were regularly weighed during time with a balance precision of $0.1 \mathrm{mg}$ until the sorption equilibrium was reached. The solvent weight fraction in the polymer was then plotted as a function of time.

\subsubsection{Pervaporation Assessment by Gravimetry}

Samples of dimensions $50 \times 50$ were cut in extruded films or in injection molded plates to study their barrier property to biofuel at $40^{\circ} \mathrm{C}$ by gravimetry. Prior testing, the thickness of the samples was carefuly measured, and in the case of PA6, samples were dried overnight at
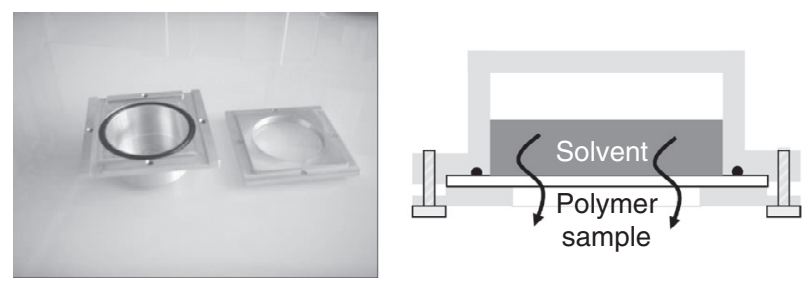

Figure 1

Picture of a permeation cup and configuration of the gravimetric pervaporation experiment.

$110^{\circ} \mathrm{C}$ under vacuum. Polymer samples were then fixed to aluminum permeation cups filled with the solvent or the solvent mixture and comprising a Viton sealing joint, a picture of the permeation cup being shown in Figure 1.

During the pervaporation experiment, the polymer surface was directly in contact with the solvent (no air space between the polymer and the solvent) and the exchange surface between the polymer and the environment consisted in a disc of radius equal to $2 \mathrm{~cm}$ (exchange surface $=12.56 \mathrm{~cm}^{2}$ ). The permeation cup was then introduced in an oven regulated in temperature $\left(40^{\circ} \mathrm{C}\right)$ and in hygrometry $(20 \%)$, and the set (permeation cup + polymer sample + solvent) was weighed during time with a balance precision of $0.1 \mathrm{mg}$. The weight loss divided by the exchange surface and multiplied by the sample thickness (normalized weight loss) was then plotted as a function of time. The derivative of this normalized weight loss as a function of time was then calculated, the obtained value being called hereafter "reduced Flux - J.L" because it corresponds to a solvent flux (J) related to specimen thickness (L). During the pervaporation experiment, the reduced flux firstly remains close to 0 during a certain time period (induction period), and then it increases progressively until it reaches the stationary state. The value of the reduced flux at the stationary state was used for defining the permeability of the sample. Another parameter called "time-lag" was also determined: it corresponds to the end of the induction period and was determined 


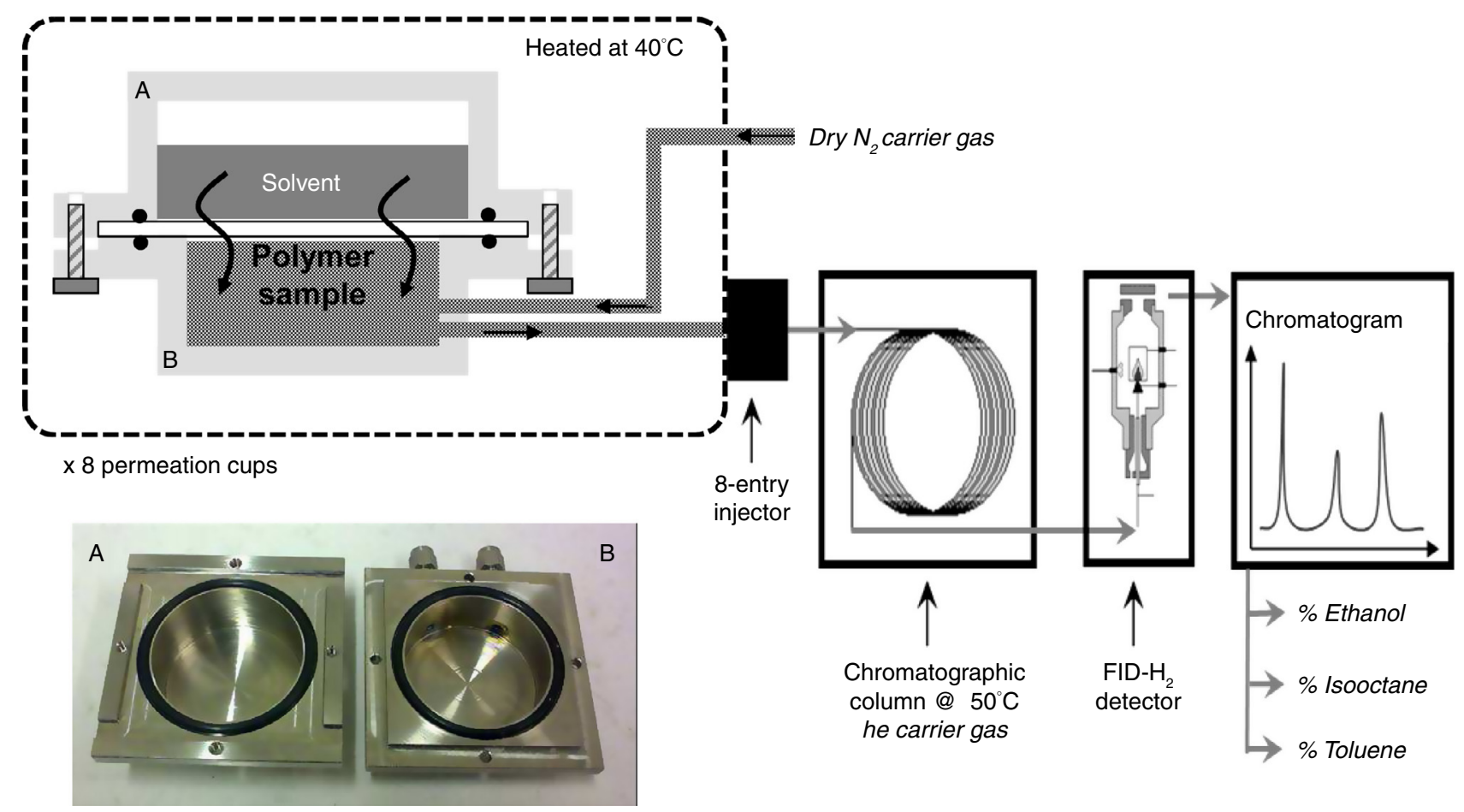

Figure 2

Set-up for analyzing the solvent flux by FID gas chromatography.

as the intersection of the tangent of the normalized weight loss at the stationary state and the $x$-axis (Fig. 6).

\subsubsection{Pervaporation Assessment by FID Gaz Chromatography}

In order to analyze the composition of the solvent flux permeating through the polymer sample, a variant of the permeation cup described in the previous paragraph was connected to an Agilent G1530N Gas Chromatograph (GC) equipped with a FID. The GC was equipped with a Heliflex AT-1 non-polar column, a FID detector, and an 8-entry 1:50 splitless injector (injection volume $=$ $50 \mu \mathrm{L}$ ) with a fixed split ratio of $1: 1$. The carrier gas from the sample to the injector was dry nitrogen with a flux set at $15 \mathrm{~mL} / \mathrm{min}$, and from the injector to the chromatographic column, helium with a flux set at $20 \mathrm{~mL} / \mathrm{min}$ was used as the carrier gas. Both the injector and the column were heated at $50^{\circ} \mathrm{C}$. The solvent vapors were separated in the chromatographic column and quantified by the FID detector. The result of the experiment was a chromatogram evidencing until 3 peaks associated to ethanol, toluene and isooctane, the surface of the peaks being proportional to their concentration via a proper calibration constant. Thanks to the selection valve,
8 permeation cups containing the polymer and the solvent could be connected to the GC-setup, each sample being analyzed once in one hour. The permeation cups were placed in an oven set at $40^{\circ} \mathrm{C}$, the connection between the sample and the GC-FID being also heated at $40^{\circ} \mathrm{C}$. A schematization of the experimental setup is shown in Figure 2.

\section{RESULTS \& DISCUSSION}

\subsection{Characterization of the Crystallinity}

It is generally accepted that diffusion of small molecules in semi-crystalline polymers mainly occurs at the solid state in the amorphous phase of the polymer, the accessibility of crystalline domains to solvents being very limited [13, 14]. A direct consequence of this restricted accessibility is that permeability depends on crystalline fraction [15], and in addition, for a given crystalline fraction, it has been shown that the crystalline structure of PA6 also affects the barrier properties of polyamide 6 , notably in presence of ethanol or ethanol-toluene mixtures [16]. In order to interpret the permeability results 
TABLE 2

Crystalline fraction of the different materials determined by DSC

\begin{tabular}{l|c|c|c|c|c|c|c}
\hline Polymer & \multicolumn{5}{c}{ PA6 } & HDPE \\
\hline Process & \multicolumn{5}{|c|}{ Film cast extrusion } & \multicolumn{2}{c}{ Injection molding } \\
\hline Thickness & $50 \mu \mathrm{m}$ & $125 \mu \mathrm{m}$ & $200 \mu \mathrm{m}$ & $500 \mu \mathrm{m}$ & $800 \mu \mathrm{m}$ & $1 \mathrm{~mm}$ & $1 \mathrm{~mm}$ \\
\hline Xc $(\%)-(+/-3 \%)$ & 31 & 30 & 30 & 30 & 32 & 34 & 65 \\
\hline
\end{tabular}

obtained on materials processed in different conditions (for instance film casting versus injection molding), it is thus of great importance to accurately characterize the crystalline morphology of the materials.

Table 2 firstly shows the crystalline fraction of the different specimens determined by DSC. Crystalline fraction of HDPE $(65 \%)$ is much more important than the one of PA6 (30-35\%). The crystalline fraction in PA6 films does not seem to depend on film thickness, and the mean value of $31 \%$ obtained for films is close to the one obtained for the PA6 injection molded plate $(34 \%)$.

The crystalline structure of the $50 \mu \mathrm{m}$ PA6 film and the $1 \mathrm{~mm}$ PA6 injection molded plate were then characterized by WAXS, the diffraction patterns being shown in Figure 3.

The $50 \mu \mathrm{m}$ extruded film and the $1 \mathrm{~mm}$ injection molded plates both exhibit one main intense peak at 2 theta $=21^{\circ}$ as well as one minor peak at 2 theta $=10^{\circ}$, suggesting the presence in both samples of mainly the gamma phase. The broadening of the main peak for the injection molded sample suggests the additional presence of a small fraction of either the alpha phase, or the metastable beta phase [17].

The spherulite structure was finally assessed by polarized optical microscopy, the obtained pictures of the extruded films and the injection molded plate being shown in Figure 4.

Well defined spherulites with an average diameter of 5-10 $\mu \mathrm{m}$ are observed on the films of different thicknesses as well as on the injection molded plate. But contrary to the extruded films, the injection molded plate exhibits a $10 \mu \mathrm{m}$ skin free of spherulites, suggesting that the cooling condition in the injection molding process is more severe (i.e. fast cooling), than the cooling condition in the film casting extrusion process. This is consistent with the temperature of the cooling devices $\left(80^{\circ} \mathrm{C}\right.$ for the mold used in injection-molding process and $125^{\circ} \mathrm{C}$ for the Chill-Roll used in film cast extrusion)

To conclude on the crystalline structure of the studied materials, it seems that the crystalline fraction and the crystalline structure (i.e. crystalline lattice) are similar in the films presenting different thicknesses and in the

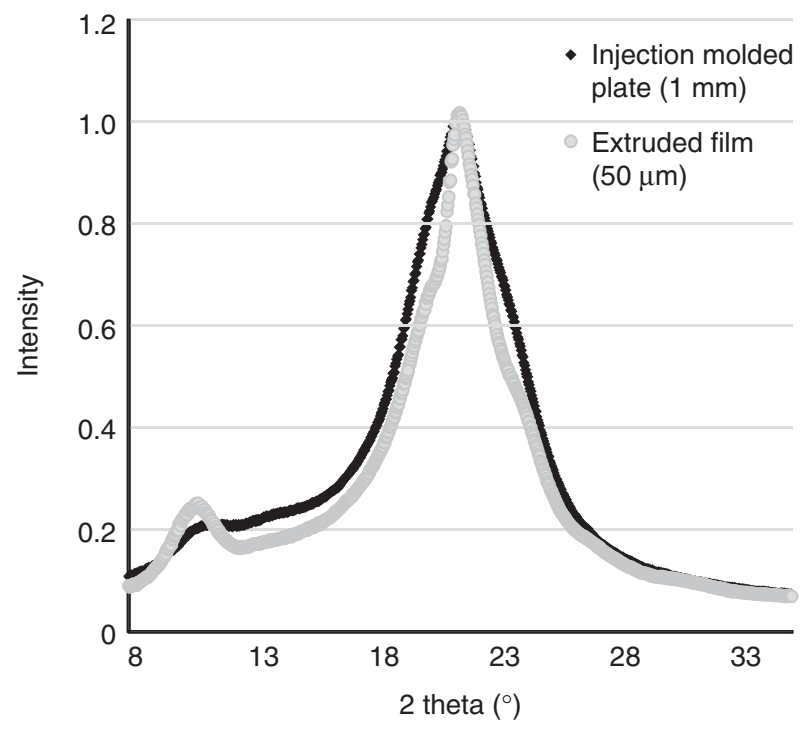

Figure 3

X-ray Diffraction patterns of the $50 \mu \mathrm{m}$ PA6 film and the $1 \mathrm{~mm}$ PA6 injection molded plate at room temperature.

injection molded plate $\left(X_{c} \sim 32 \%\right.$, presence of mainly the gamma phase). But at the scale of the spherulites, a $10 \mu \mathrm{m}$ thick skin deprived of spherulites is only seen in the injection molded plate. Concerning HDPE, it should be kept in mind that its crystalline fraction $(65 \%)$ is far more important than the one of PA6.

\subsection{Analysis of Sorption and Permeation Data in Presence of E10}

Figure 5 shows the sorption curves obtained by gravimetry of $1 \mathrm{~mm}$ thick PA6 and HDPE plates immerged in E10 at $40^{\circ} \mathrm{C}$, the dash lines representing only guides for the eye.

The amount of E10 sorbed at the thermodynamic equilibrium in PA6 and HDPE is very close (7.5-8\%), but if we consider that solvents penetrate only the amorphous phase, it turns out that the amount of E10 in the amorphous phase of HDPE (23\%) is higher than the one 

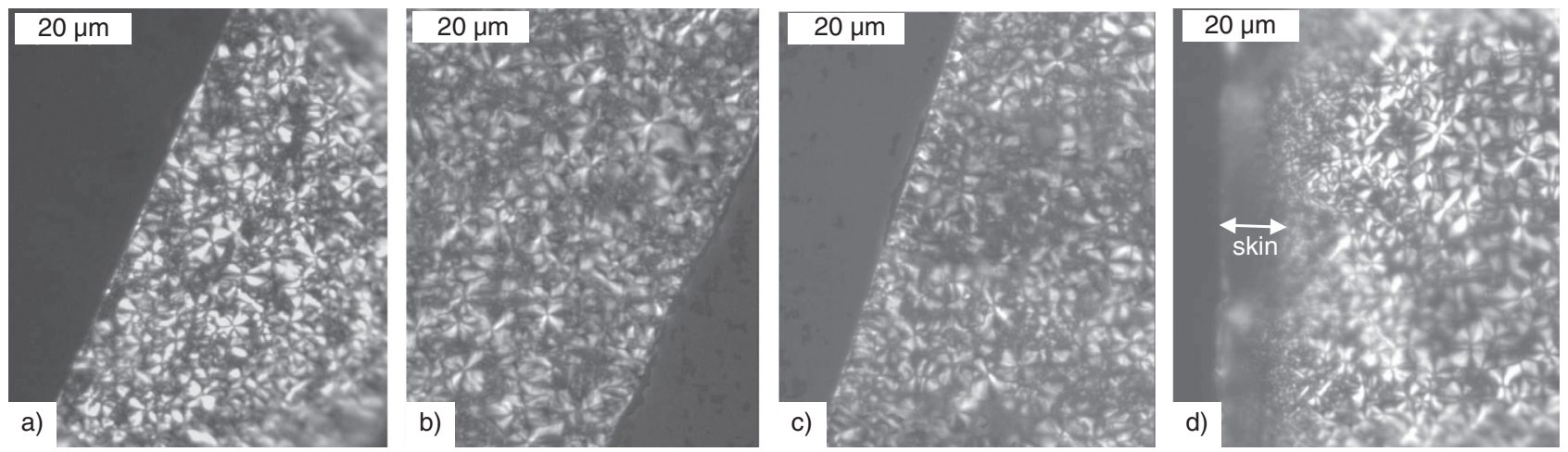

Figure 4

Polarized optical micrographs of a) $50 \mu \mathrm{m}$ film, b) $200 \mu \mathrm{m}$ film, c) $800 \mu \mathrm{m}$ film, d) $1 \mathrm{~mm}$ injection molded plate.

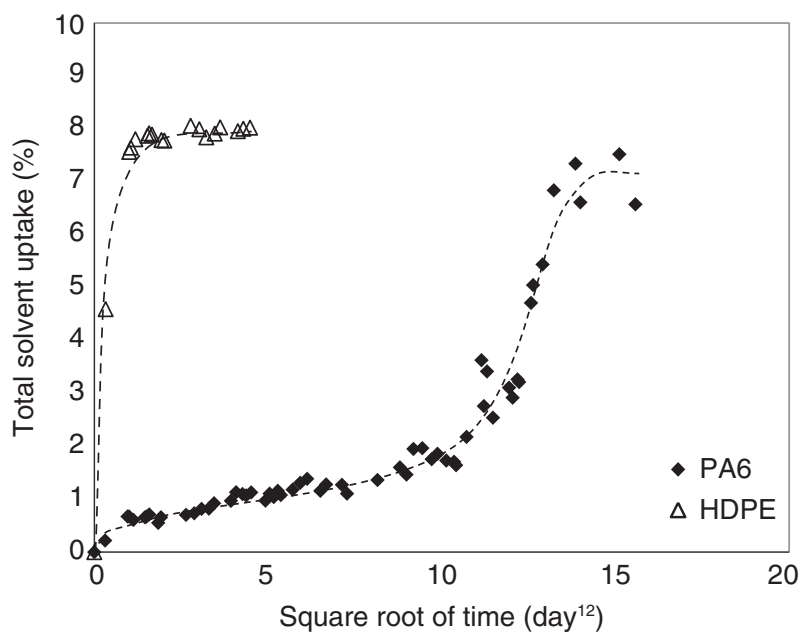

Figure 5

E10 uptake as a function of the square root of time for $1 \mathrm{~mm}$ thick PA6 and HDPE plates at $40^{\circ} \mathrm{C}$.

in the amorphous phase of PA6 (12.3\%), the equation used for calculating solvent intake in the amorphous phase being defined as:

$$
G_{\text {amorphous phase }}=\frac{G_{\text {total }}}{\left(1-X_{c}\right)}
$$

with $G_{\text {amorphous phase }}$ the solvent uptake in the amorphous phase, $G_{t o t}$ the measured solvent uptake and $X_{c}$ the crystalline fraction of the polymer.

Figure 5 also shows that the sorption kinetics in HDPE is much faster than that of PA6. In the case of $1 \mathrm{~mm}$ thick HDPE sample, swelling is completed after 1 day whereas in the case of $1 \mathrm{~mm}$ thick PA6, 200 days are needed to reach the sorption equilibrium. The evolution of solvent uptake with the square root of time is not linear in the case of PA6, which suggests a non fickian behavior. This kind of diffusion called abnormal or Case-II diffusion is generally observed when the solvent is able to modify the molecular mobility of the polymer during the sorption experiment, this modification consisting in decreasing the glass temperature of the polymer until a value equal or inferior to the testing temperature [18-21]. In the first stages of abnormal diffusion, the solvent is absorbed following a fickian diffusion (governed by the solvent concentration gradient), but at some point (corresponding roughly in our case to the inflexion point observed on the PA6 sorption curve of Fig. 5), the concentration of the polymer will be such, that locally the presence of the solvent will allow the relaxation of the polymer at the testing temperature. In this zone, the diffusion of the solvent is accelerated since the polymer is plasticized, and thus there is the appearance of a plasticization front. The diffusion is no longer governed by the solvent concentration gradient, but rather by the ability of the solvent to modify the molecular mobility of the polymer. We showed in a previous work [22] that the solvents present in E10, and mainly ethanol, strongly impacts the molecular mobility of the amorphous phase of PA6 (Tg of PA6 swollen with E10 $=-30^{\circ} \mathrm{C}$ ). Consequently, at a testing temperature of $40^{\circ} \mathrm{C}$, PA6 is expected to become rubbery during the sorption experiment. The non fickian behavior of PA6/ethanol systems has been described and discussed in the literature, on the basis of heuristic modified diffusionrelaxation models $[19,23]$ or on the basis of a thermodynamical approach [24].

Figure 6 shows then the pervaporation curves obtained by gravimetry of $1 \mathrm{~mm}$ thick HDPE and PA6 plates put in contact with fuel $\mathrm{E} 10$ at $40^{\circ} \mathrm{C}$. In the case 
of HDPE, pervaporation starts quasi immediately, whereas in the case of PA6, no significant weight loss is observed before 40-50 days (time-lag $~ 50$ days). The small initial weight gain observed on the PA6 curve should be attributed to water intake, initially dried polyamide progressively equilibrating at the current hygrometry level of the pervaporation test $(20 \%$ in the present case).

In order to precisely determine the E10 permeabilities of PA6 and HDPE, the derivative of the normalized weight loss as a function of time (Reduced Flux J.L.) is plotted in Figure 7. In the case of HDPE, the reduced flux at the stationary state is about $65 \mathrm{~g} . \mathrm{mm} / \mathrm{m}^{2}$.day whereas it is only 2 g. $\mathrm{mm} / \mathrm{m}^{2}$.day in the case of PA6.

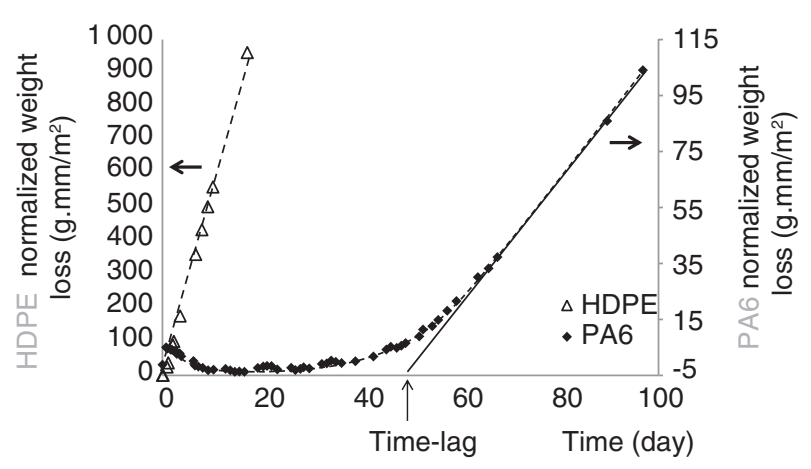

Figure 6

Weight loss as a function of time for $1 \mathrm{~mm}$ thick PA6 and HDPE plates in presence of E10 at $40^{\circ} \mathrm{C}$ (HDPE: left axis, PA6: right axis).

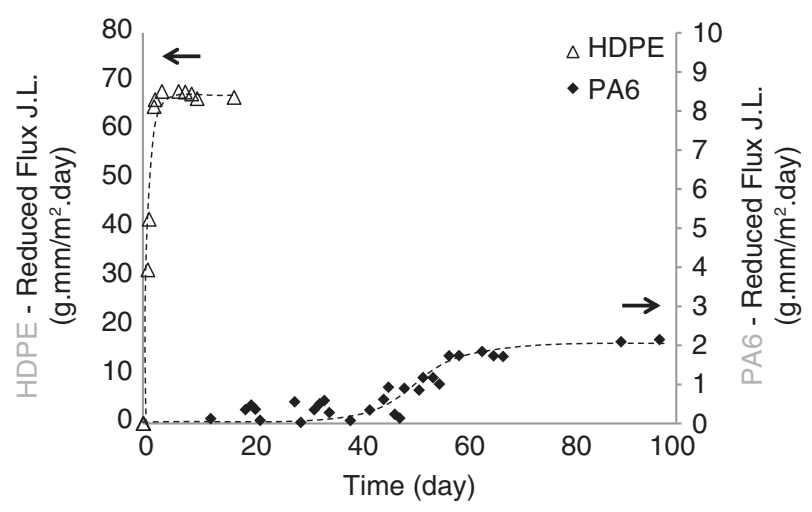

Figure 7

Reduced Flux (J.L.) as a function of time for $1 \mathrm{~mm}$ thick PA6 and HDPE plates in presence of $\mathrm{E} 10$ at $40^{\circ} \mathrm{C}$ (HDPE: left axis, PA6: right axis).
It should be also pointed out that 60 days are necessary for PA6 to reach a stationary regime whereas less than one day is required for HDPE. It is known that permeability $(P)$ is driven by the solubility $(S)$ and the diffusion coefficient $(D)$ of the diffusing species in the polymer, the relationship $P=S D$ being valid in the case of fickian diffusion. But even if the diffusion is not fickian, it is clear that $P$ depends on both $S$ and $D$. In the present case, it is shown that HDPE and PA6 exhibits similar E10 solubilities, but diffusion kinetics is much faster in the case of HDPE. This fast diffusion kinetics in HDPE may thus be at the origin of the poor E10 barrier property of HDPE in comparison with the one of PA6. It should be underlined that PA6 E10 permeability is 35 times lower than the one of HDPE, despite a crystalline fraction in PA6 divided by almost 2.

\subsection{Effect of Ethanol Content}

The influence of ethanol content in the fuel on the barrier properties of HDPE and PA6 was then studied. Different ethanol/toluene/isooctane mixtures containing different ethanol fractions were prepared according to the protocol described in the experimental section, and HDPE and PA6 samples were immerged in these mixtures at $40^{\circ} \mathrm{C}$ until the sorption equilibrium was reached. The solvent uptake at the equilibrium measured by gravimetry for both polymers is plotted in Figure 8 as a function of the ethanol content in the fuel. In the case of PA6, solvent uptake at the equilibrium increases with ethanol content, whereas the opposite is observed for

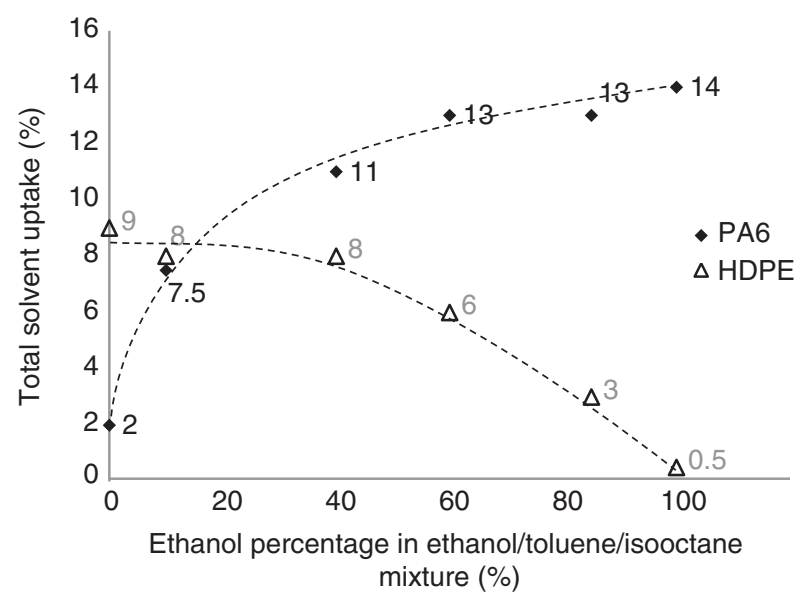

Figure 8

Solvent uptake at the equilibrium as a function of the ethanol content in fuel for PA6 and HDPE immerged at $40^{\circ} \mathrm{C}$ in ethanol/toluene/isooctane mixtures. 


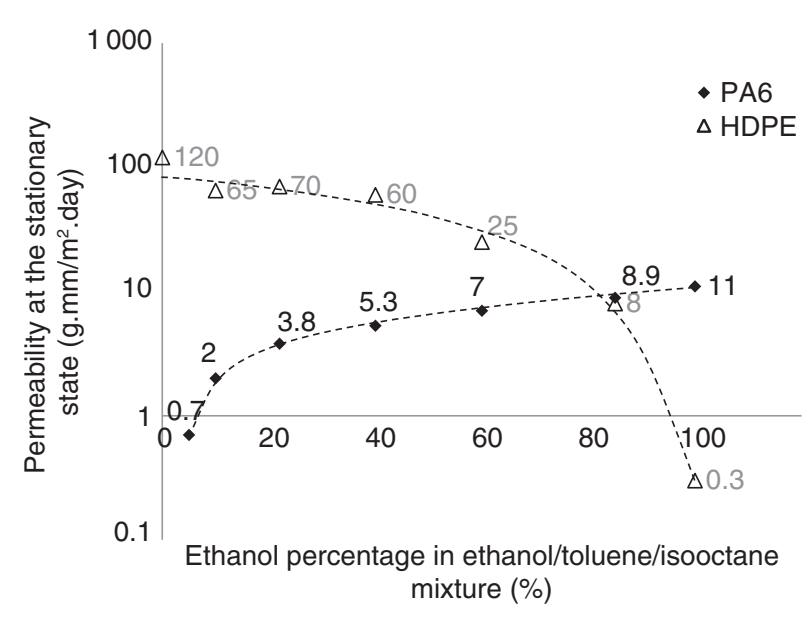

Figure 9

Steady state permeability as a function of the ethanol content in fuel for PA6 and HDPE put in contact with ethanol/ toluene/isooctane mixtures at $40^{\circ} \mathrm{C}$.

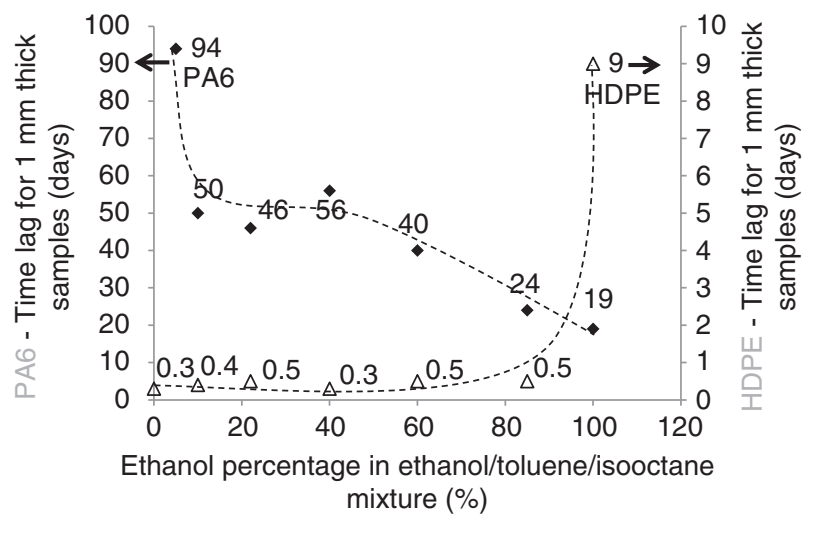

Figure 10

Time-lag values as a function of the ethanol content in fuel for $1 \mathrm{~mm}$ thick PA6 and HDPE plates put in contact with ethanol/toluene/isooctane mixtures at $40^{\circ} \mathrm{C}$.
HDPE, a similar solvent uptake for PA6 and HDPE being observed for the composition E10, as already described in the previous paragraph. The difference of polarity between PA6 and HDPE is naturally at the origin of these two opposite trends, the presence of polar amide groups in polyamide favoring the interaction with polar molecules such as ethanol. Above $10 \%$ of ethanol in the fuel, fuel uptake is larger in PA6 than in HDPE.

The influence of ethanol content in fuel on the steady state permeability measured by gravimetry is then shown in Figure 9, the values obtained for HDPE being close to data found in the literature $\left(69 \mathrm{~g} . \mathrm{mm} / \mathrm{m}^{2}\right.$.day in presence of E10 and 90 g.mm $/ \mathrm{m}^{2}$.day in presence of E0 according to Nulman et al. [1]). Similarly to the equilibrium solvent intake, permeability of PA6 increases with ethanol content whereas it decreases in the case of HDPE. But permeability values of HDPE are much higher than the ones of PA6 until $85 \%$ of ethanol in the fuel, composition for which permeability of HDPE is close to that of PA6 (8-9 g.mm $/ \mathrm{m}^{2}$.day). In the case of low ethanol content fuels (E5, E0), permeability of PA6 turns out to be at least 100 times lower than that of HDPE. It should be also pointed out that the evolution of the permeability of PA6 or HDPE with ethanol content is monotonic, no maximum suggesting a "positive synergy" being observed as it is the case for PA12, PVDF or $\mathrm{EVOH}$ in presence of methanol/toluene mixture [2].

The influence of ethanol content in the fuel on the time-lag measured during gravimetric pervaporation tests on $1 \mathrm{~mm}$ thick PA6 and HDPE samples is then shown in Figure 10. On the whole fuel composition range ( $0 \%$ to $100 \%$ ethanol), the time-lag is much higher for PA6 than for HDPE, suggesting slower diffusion kinetics for PA6 on the whole fuel composition range. The slow diffusion kinetics of E10 in PA6 between $10 \%$ and $85 \%$ of ethanol in the fuel seems to counterbalance the higher solubility observed for PA6 in Figure 8 (because the permeability of PA6 is lower than the one of HDPE on that fuel composition range). But beyond $85 \%$ of ethanol in the fuel, it seems that the slower diffusion kinetics of PA6 does not counterbalance the higher solubility of polyamide, a poorer barrier property being observed in the case of PA6 in presence of E100.

In the case of PA6, three regimes can be distinguished: time-lag firstly strongly decreases between 5 and $10 \%$ of ethanol in the mixture (we could not determine the timelag of PA6 in presence of E0 in a reasonable time scale), then a plateau is observed between 10 and $60 \%$ of ethanol in the mixture, and finally, time-lag slowly decreases between $60 \%$ and $100 \%$ of ethanol in the mixture. The strong decrease of time-lag between 0 and $10 \%$ associated to a strong increase of the solubility on that fuel composition range lead to a strong increase of permeability, and between $10 \%$ and $100 \%$, the presence of a plateau or a moderate decrease of the time lag associated to a moderate increase of solubility lead to a moderate increase of the permeability.

\subsection{Effect of Sample Thickness}

The influence of sample thickness on the barrier properties of PA6 was then studied thanks to the extruded films 

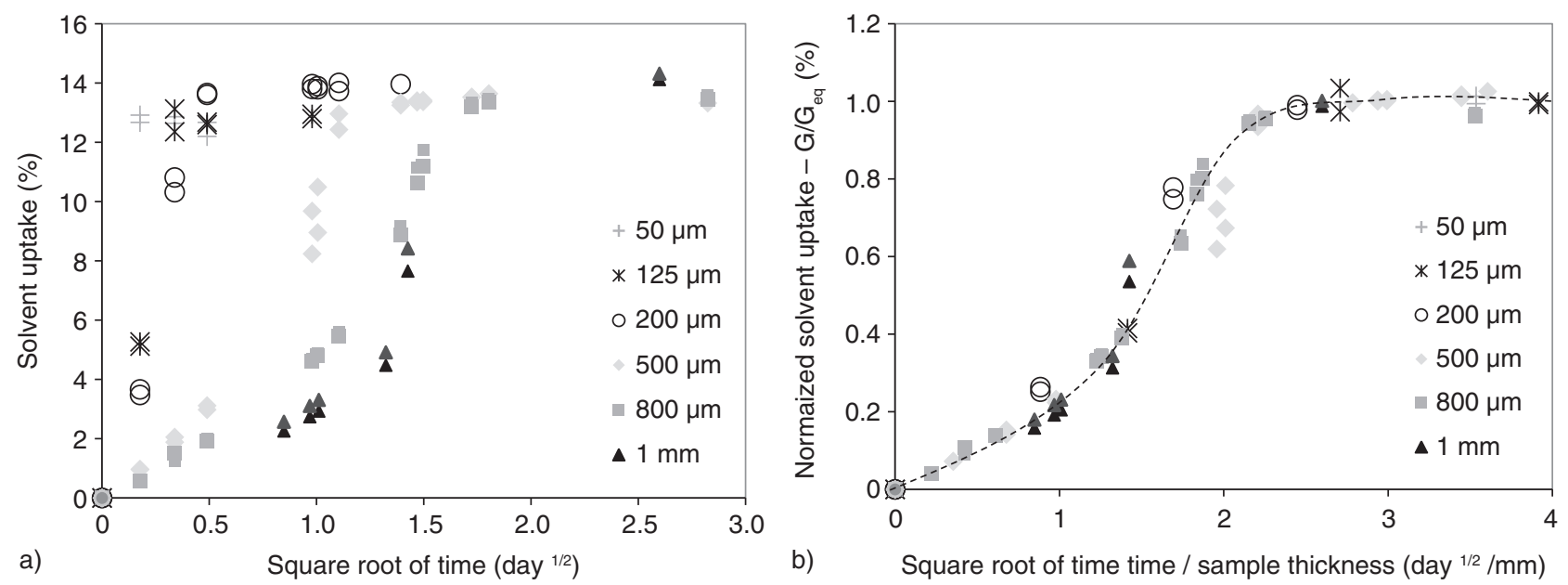

Figure 11

Ethanol sorption at $40^{\circ} \mathrm{C}$ of PA6 samples of various thicknesses a) solvent uptake as a function of square root of time b) normalized curve: solvent uptake divided by the uptake at the equilibrium as a function of the square root of time divided by sample thickness.
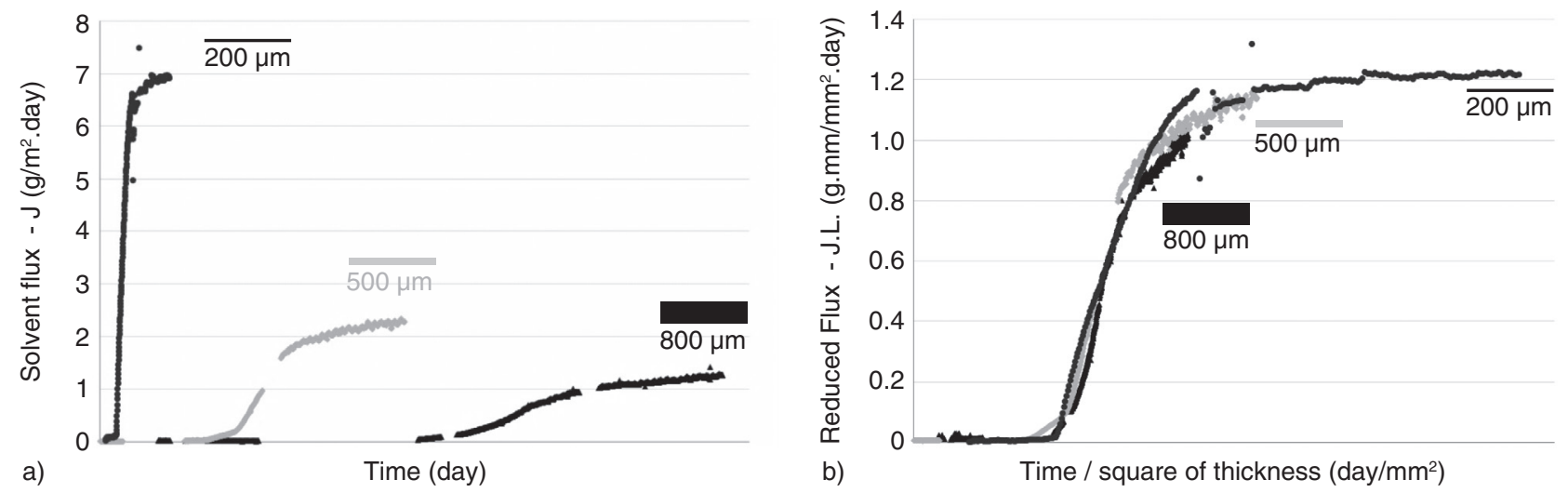

Figure 12

E10 pervaporation of PA6 samples presenting various thicknesses at $40^{\circ} \mathrm{C}$ a) solvent flux as a function of time b) reduced flux as a function of the time divided by the square of the thickness.

and the injection molded plate presenting different thicknesses varying from $50 \mu \mathrm{m}$ to $1 \mathrm{~mm}$. The influence of sample thickness on the ethanol sorption of PA6 measured by gravimetry at $40^{\circ} \mathrm{C}$ is firstly shown in Figure 11 .

Figure 11a shows that solvent uptake at the equilibrium varies little with sample thickness, which is consistent with the fact that crystalline fraction as well as crystalline lattice nature are similar in the different samples. Then, the thinner the sample, the faster the sorption kinetics. By normalizing the $\mathrm{x}$ axis (square root of time) by the sample thickness (Fig. 11b), a mastercurve is obtained; suggesting that ethanol diffusion kinetics in
PA6 evolves with the square of the thickness. Since ethanol diffusion in PA6 is not fickian (as attested by the sigmoidal sorption curves), this result was not expected. The presence of a $10 \mu \mathrm{m}$ skin deprived of spherulites in the injection molded sample does not seem to affect neither the solvent uptake nor the diffusion kinetics.

The influence of sample thickness on the permeability of PA6 in presence of $\mathrm{E} 10$ at $40^{\circ} \mathrm{C}$ was then studied on the basis of results obtained with FID gas chromatography on films presenting 3 different thicknesses of 200 , 500 and $800 \mu \mathrm{m}$. Figure 12a shows that the thinner the sample, the higher the solvent flux and the faster the 

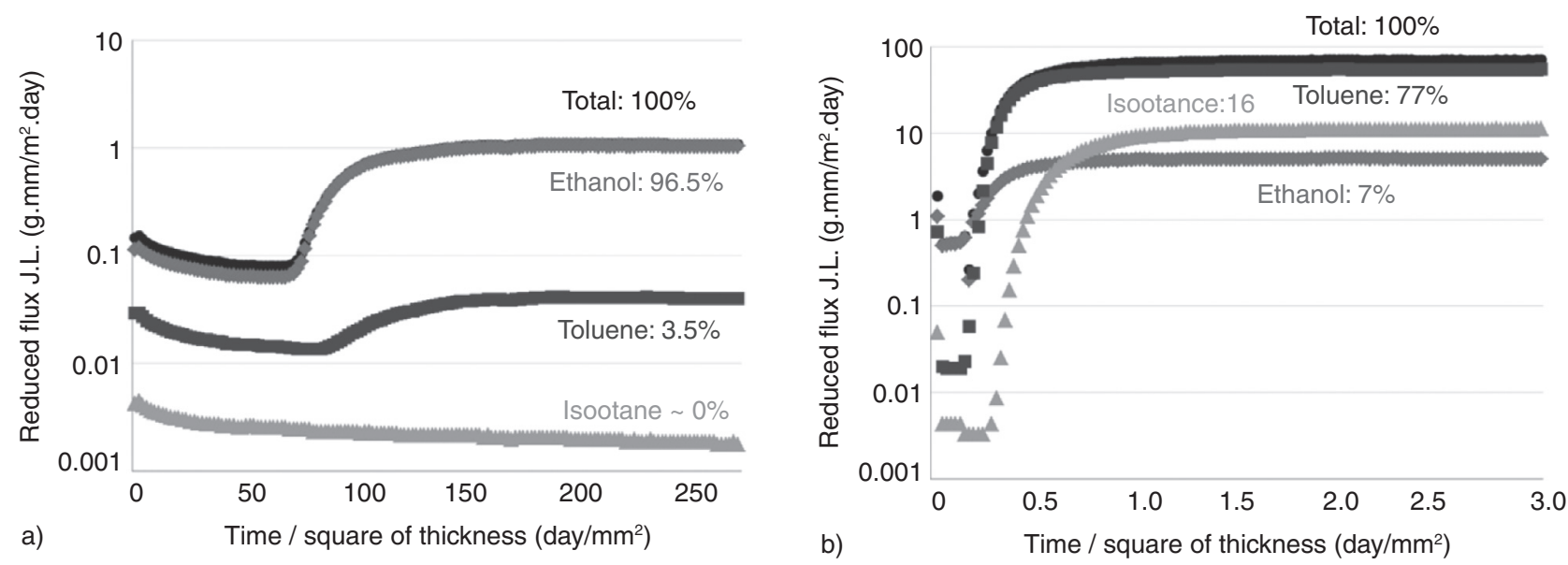

Figure 13

Separate solvents contribution to the reduced flux measured by FID gas chromatography at $40^{\circ} \mathrm{C}$ in presence of E10 as a function of the normalized time a) PA6, b) HDPE.

pervaporation kinetics. By normalizing the $y$-axis (solvent flux) by sample thickness and the $x$-axis (time) by the square of the sample thickness, a mastercurve is obtained. Similarly to sorption kinetics, permeation kinetics turns out to evolve with the square of the sample thickness. To summarize, it is important to underline that despite the pronounced plasticizing effect of ethanol on PA, and a resulting anomalous diffusion behaviour attested by sigmoidal sorption curves, sorption or permeation kinetics of biofuels in PA6 turns out to evolve with the square of the sample thickness (observed also in the case of PA6 in presence of fuels containing 5\% or $85 \%$ of ethanol - results not shown here).

The validation of the evolution of pervaporation kinetics with the square of sample thickness allows extrapolating what would be the pervaporation kinetics of thick parts such as fuel tanks. For $1 \mathrm{~mm}$ thick samples, the time lag is about 75 days for extruded films (Fig. 12b, result obtained by FID chromatography) and 40 days for the injection molded plate (Fig. 7, result obtained by gravimetry). The difference between these results could originate from differences linked to polyamide processing (extrusion versus injection molding), pervaporation measurement (FID chromatography versus gravimetry), or the hygrometry level associated to the experiment (dry condition versus HR20). If we consider the minimum value of 40 days for the $1 \mathrm{~mm}$ injection molded plate, a simple calculation shows that the time lag for a $3 \mathrm{~mm}$ part will be $40 \times 3^{2}=360$ days, i.e. about 1 year. But a pervaporation test that lasts 1 year would not be long enough to assess the stationary state permeability. Results on $1 \mathrm{~mm}$ injection molded plate show that the stationary state permeability is obtained after 60 days, i.e. after a relatively long transient regime. For a $3 \mathrm{~mm}$ thick part, the extrapolation indicates that the stationary state permeability would be reached after $60 \times 3^{2}=18$ months. The results obtained on films (time lag: 75 days, steady state: 200 days), imply an extrapolation for $3 \mathrm{~mm}$ thick parts of almost 2 years for the time lag and 5 years for the stationary state. Beyond the differences between films characterized by FID chromatography and injection molded plates characterized by gravimetry, these results show that the test duration necessary to assess the stationary state permeability of polyamides is very long regarding the time scale of the actual standards for assessing the fuel emissions of vehicles. Indeed, Euro 5 standard implies a measurement on a vehicle after $3000 \mathrm{~km}$ of rolling, the time needed to complete such a distance being of the order of magnitude of a few months. As a consequence, if a SHED evaluation is performed on a PA6 fuel tank according to the actual standards, the measured emission could be close to zero, because the PA6 tank is likely to be still in its "time-lag" period. This is not the case for HDPE which exhibits much faster pervaporation kinetics, and for which a stationary state permeability should be obtained after $3000 \mathrm{~km}$ of rolling (stationary state permeability of HDPE for $1 \mathrm{~mm}$ thick sample obtained in less than one day). This issue of underestimating the permeability of polymers because of a too short period of exposition of the tank to solvents is well known by automotive manufacturers who often apply a soaking procedure of the 

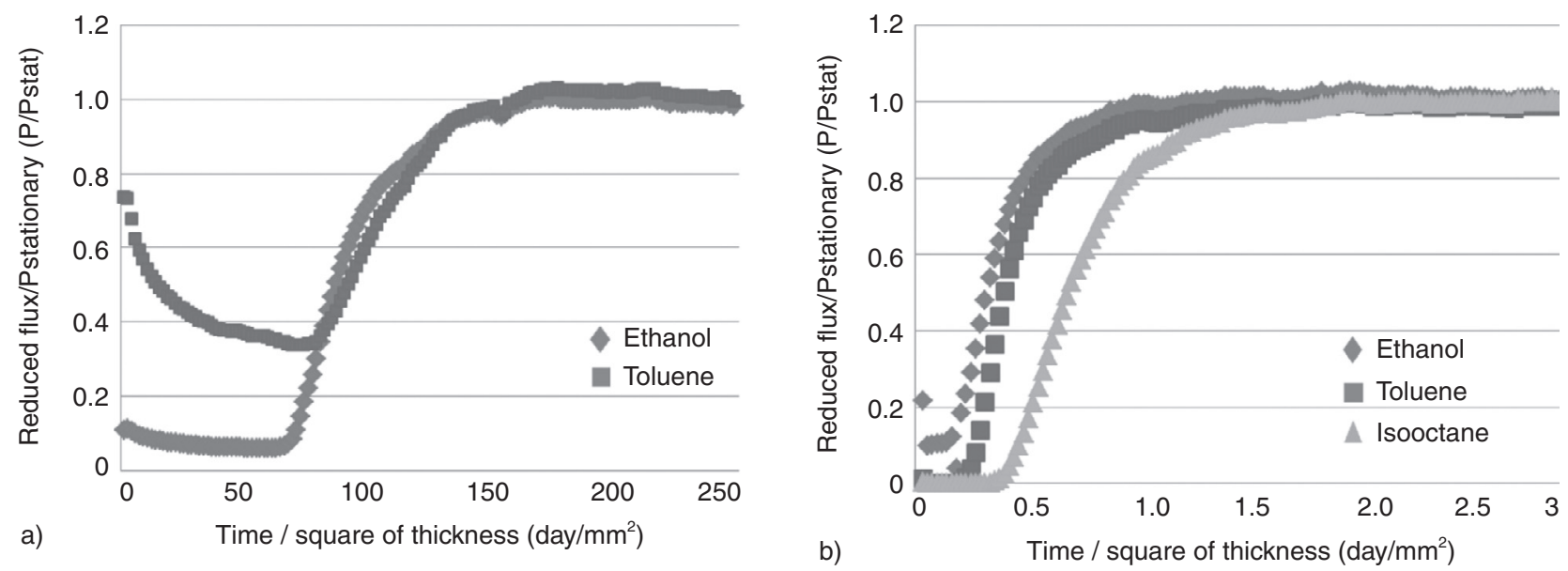

Figure 14

Reduced flux over permeability at the stationary state for each solvent flux measured by FID gas chromatography at $40^{\circ} \mathrm{C}$ in presence of E10 a) PA6, b) HDPE.

tanks of 20-25 weeks before the SHED measurement. But it turns out that this extended soaking procedure remains short in regards of fuel diffusion kinetics in PA6.

In order to accelerate the pervaporation experiment, thin specimens should be preferred, but in order to avoid changing polyamide processing for the obtention of these thin specimens (for example extruding films instead of blow molding fuels tanks), which could alter the PA microstructure and further its barrier properties, one possibility is to thin out the part. A good correlation was indeed obtained between machined samples for which the thickness was reduced from $1 \mathrm{~mm}$ to $0.3 \mathrm{~mm}$, and non-machined samples obtained directly from the injection molding process (results not shown here).

\subsection{Analysis of the Solvent Flux by FID Gas Chromatography}

The composition of solvent flux was then studied by FID gas chromatography for PA6 and HDPE put in contact with fuels containing various ethanol contents at $40^{\circ} \mathrm{C}$. Figure 13 firstly shows the results obtained for PA6 (200 $\mu \mathrm{m}$ thick extruded film) and HDPE $(1 \mathrm{~mm}$ thick injection molded plate) in presence of E10. In the case of PA6 + E10, the species contained in the solvent flux are mainly ethanol $(96.5 \%)$, a little amount of toluene $(3.5 \%)$ and no detectable amount of isooctane. In the case of HDPE + E10, the solvent flux is composed of $77 \%$ of toluene, $16 \%$ of isooctane and $7 \%$ of ethanol. The slight decrease of the fluxes of ethanol, toluene and isooctane observed for PA6 at the very beginning of the permeation experiment could be attributed to residual solvent traces which are present on the downstream part of the permeation cell, and which are progressively evacuated.

In order to compare the solvent diffusion kinetics, the ratio of the reduced flux on the permeability at the stationary state was plotted in Figure 14 for each solvent. A quite unexpected result is that both in the cases of PA6 and HDPE, diffusion kinetics of ethanol and toluene turn out to be relatively close, permeation of both solvents starting quite simultaneously (but it should be more accurately confirmed in the case of PA6 because the issue of residual traces of toluene hide the beginning of toluene permeation). Isooctane diffusion kinetics in HDPE appears to be slower than those of ethanol and toluene, isooctane starting to permeate slightly later. And as already discussed in Section 2.4., the diffusion timescales in PA6 and in HDPE are very different, solvents diffusion being much faster in HDPE than in PA6.

Figure 15 shows then the ethanol percentage in the pervaporation solvent flux measured at $40^{\circ} \mathrm{C}$ by FID gas chromatography as a function of ethanol content in the fuel for the two samples described previously. On the whole fuel composition range, ethanol is by far the main species present in the solvent flux of PA6. On the contrary, hydrocarbons are the main components of the solvent flux of HDPE, $30 \%$ of ethanol being nevertheless measured in the solvent flux of HDPE in contact with E85.

These results point out two important facts. Firstly, as ethanol is less toxic than aromatic hydrocarbons such as toluene, the use of polyamide should be preferable from the Health and Safety point of view. Indeed, if we take 


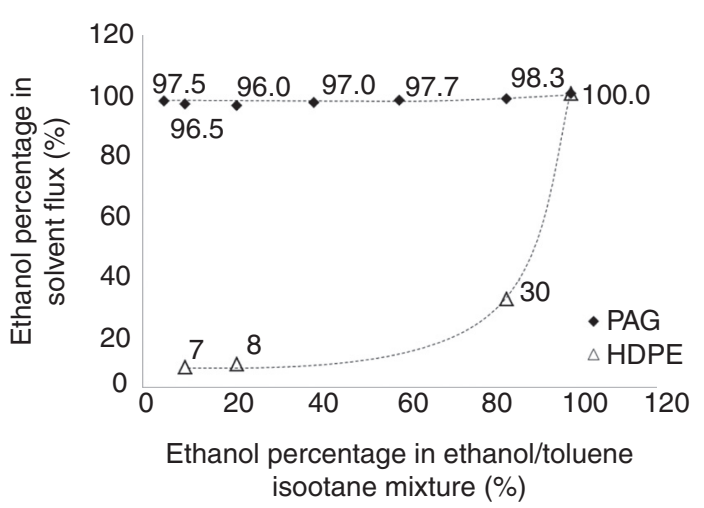

Figure 15

Ethanol percentage in the pervaporation solvent flux as a function of ethanol content in ethanol/toluene/isooctane mixtures - comparison of PA6 (200 $\mu \mathrm{m}$ extruded film) and HDPE (1 mm injection molded plate).

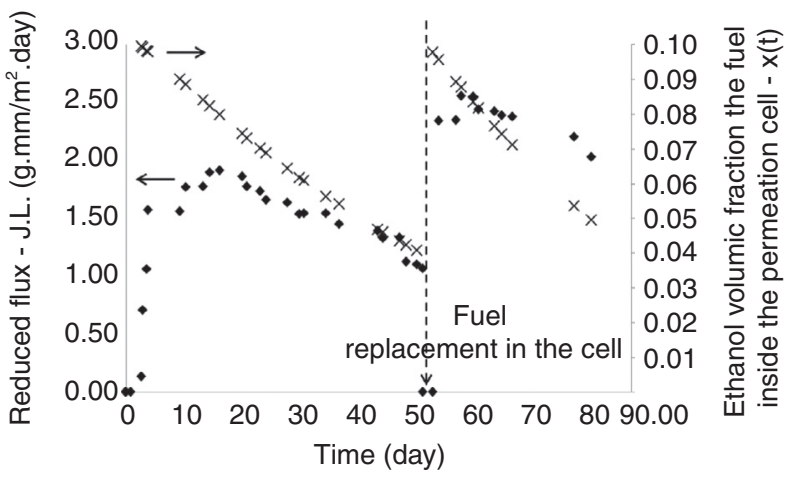

Figure 16

Illustration of the influence of fuel composition evolution during the experiment on the permeability value measured by gravimetry (result obtained on PA6 $200 \mu \mathrm{m}$ thick film in presence of $\mathrm{E} 10$ at $40^{\circ} \mathrm{C}$ ). into account both the vapors composition and the lower pervaporation value of PA6 $\left(2 \mathrm{~g} . \mathrm{mm} / \mathrm{m}^{2}\right.$.day for PA6 instead of $65 \mathrm{~g} . \mathrm{mm} / \mathrm{m}^{2}$.day for HDPE in presence of E10), it turns out that the hydrocarbons content in the permeant species is 900 times lower for PA6 + E10 than for HDPE + E10. Secondly, the vapors composition difference between PA6 and HDPE has to be kept in mind if the two materials are characterized by applicative assessment methods such as the SHED test. Indeed, SHED experiments involve the use of a FID detector but no chromatographic column that allows the separation of the species. SHED tests are generally calibrated with propane, which implies that all the molecules detected by the SHED FID detector are "seen" as propane molecules. But ethanol and hydrocarbons should not be counted up the same because the response coefficient of ethanol is much lower than that of hydrocarbons. If this difference is not taken into account (as it is the case for the SHED test), this will lead to an underestimation of the PA6 permeability. The relationship between the permeability measured by SHED and the permeability measured by gravimetry or by FID gas chromatography (with species separation and appropriate calibration) could be basically given by Equation (3):

$$
P_{S H E D}=P_{\text {real }}\left(\frac{x_{\text {etoh }}}{f}+x_{\text {hyd }}\right)
$$

with $P_{S H E D}$ the permeability measured by SHED experiment, $P_{\text {real }}$ the permeability measured by gravimetry or by FID gaz chromatography (with species separation and appropriate calibration), $x_{\text {etoh }}$ the ethanol content in the permeant species, $x_{\text {hyd }}$ the hydrocarbons content in the permeant species, and $f$ the ratio between the response coefficient of hydrocarbons and the response coefficient of ethanol determined during the calibration of the FID detector (in our case, 5). In presence of E10, the simple numerical application of Equation (1) predicts that the permeability measured by SHED will be 4 times lower than that measured by gravimetry for PA6, whereas it will be almost unchanged in the case of HDPE.

\subsection{Influence of Fuel Composition Evolution}

It was shown in the previous paragraph that there is a preferential diffusion of polar molecules in the case of PA6 or apolar molecules in the case of HDPE, and a consequence of this preferential diffusion can be an evolution of the fuel composition present in the permeation cell (or in the fuel tank). As pervaporation is strongly dependent on the fuel composition (namely the ethanol content), this can lead to a variation of the permeability value during the experiment.

Figure 16 shows on its left axis the reduced flux measured by gravimetry of a $200 \mu \mathrm{m}$ thick PA6 film in presence of $\mathrm{E} 10$ at $40^{\circ} \mathrm{C}$ as a function of time.

The reduced flux seems to stabilize around 10 days to a value close to $2 \mathrm{~g} . \mathrm{mm} / \mathrm{m}^{2}$.day, but afterwards, reduced flux progressively decreases with time. The evolution of 
the ethanol content in the permeation cell was then calculated according to Equation (4):

$$
x(t)=x_{0}-\frac{f \cdot \Delta m(t)}{d_{\text {etoh }} \cdot V_{0}}
$$

with $x(t)$ the volumic fraction of ethanol inside the permeation cell at a given time $t, x_{0}$ the initial volumic fraction of ethanol inside the permeation cell $\left(x_{0}=0.10\right.$ in the case of E10), $f$ the weight fraction of ethanol present in the solvent flux $(f=0.965$ in the case of PA6 + E10, according to the results presented in Sect. 4), $\Delta m(t)$ the total weight loss at a given time $t, d_{\text {etoh }}$ the density of ethanol at the temperature of the experiment (taken as $0.79 \mathrm{~g} / \mathrm{cm}^{3}$ ), and $V_{0}$ the initial volume of solvent in the permeation cell (in our case $V_{0}=14 \mathrm{~cm}^{3}$ ). This parameter $x(t)$ is plotted as a function of time on the right axis of Figure 16 and it can be seen that after 50 days, the ethanol content in the fuel inside the permeation cell decreases from $10 \%$ to about $4 \%$, this decrease of the ethanol content being accompanied by a decrease of the reduced flux from $2 \mathrm{~g}$. $\mathrm{mm} / \mathrm{m}^{2}$.day to almost $1 \mathrm{~g} . \mathrm{mm} / \mathrm{m}^{2}$.day. In the current experiment, at 55 days, the fuel in the permeation cell was entirely replaced by a new preparation containing the right specific composition of fuel E10. Figure 16 shows that this fuel replacement induces an immediate increase of the reduced flux, reaching a value close but slightly higher than that of the reduced flux after 10 days. Then, reduced flux decreases again while the ethanol content in the permeation cell decreases.

This result obtained on a $200 \mu \mathrm{m}$ thick PA6 film illustrates what could be called the fuel exhaustion process. In the case of polyamide, it is the ethanol fraction decrease that leads to a decrease of the measured permeability, and in the case of polyethylene it is the hydrocarbons fraction decrease that leads to a decrease of the measured permeability. In order to avoid this phenomenon, it is important to have an initial volume of fuel inside the permeation cell important in comparison with the measured weight loss, and in every case, attention should be paid to attest the possible evolution of the fuel composition. In case of doubt, a simple way to proceed is to replace the fuel in the permeation cell and to see if this replacement induces an increase of the reduced flux.

From an applicative point of view, we can wonder in what extent this evolution of fuel composition induced by preferential diffusion can be an issue in real size fuel tanks. In order to estimate the fuel composition evolution kinetics in a real fuel tank, it is possible to calculate the time $t_{i}$ (in days) needed to deplete the component $i$ with a ratio $x$ according to Equation (5):

$$
t_{i}(x)=\frac{1000 V \varphi_{\text {tank }} \varphi_{i} d_{i} x}{\left(\frac{P S_{\text {exc }}}{e}\right) f_{i}}
$$

with $V$ the volume of the tank in $\mathrm{L}, \phi_{\text {tank }}$ the filling rate of the tank, $\phi_{i}$ the volumic fraction of component $i$ in the fuel, $d_{i}$ the density of the component $i$ in $\mathrm{g} / \mathrm{cm}^{3}, P$ the permeability of the polymer, $S_{\text {exc }}$ the exchange surface in the fuel tank in $\mathrm{m}^{2}, e$ the thickness of the tank in $\mathrm{mm}, f_{i}$ the weight fraction of component $i$ in the solvent flux and $x$ the ratio of the loss amount of component $i$ on the initial amount of component $i(x=1$ for complete component depletion).

A very unfavorable situation corresponds to a large tank (important exchange surface) almost empty. If we consider the following hypothesis: $80 \mathrm{~L}$ cubic fuel tank (exchange surface $1 \mathrm{~m}^{2}$ ), tank thickness of $3 \mathrm{~mm}$, filled up to $5 \%$ with E10 $\left(\phi_{\text {tank }}=0.05\right)$, permeability PA6 of $2 \mathrm{~g} . \mathrm{mm} / \mathrm{m}^{2}$.day, ethanol representing $96.5 \%$ of the permeant species $\left(f_{i}=0.965\right)$, we obtain according to Equation 5 that the time needed to completely deplete ethanol in fuel (in other words transforming E10 into E0) is 16 months for PA6. In the case of HDPE (permeability HDPE $=65 \mathrm{~g} \cdot \mathrm{mm} / \mathrm{m}^{2}$.day, ethanol representing $7 \%$ of the permeant species), the time needed to deplete hydrocarbons (in other words transforming E10 into E100) is 4.5 months.

The ratio of the time needed to deplete ethanol $(i)$ in a PA6 tank on the time needed to deplete hydrocarbons $(j)$ in an HDPE tank is then given in Equation (6):

$$
\frac{t_{i-P A 6}}{t_{j-H D P E}}=\left(\frac{P_{H D P E}}{P_{P A 6}}\right)\left(\frac{\varphi_{i}}{1-\varphi_{i}}\right)\left(\frac{d_{i}}{d_{j}}\right)\left(\frac{f_{j}}{f_{i}}\right)
$$

This ratio mainly depends on the barrier performances of the polymers in presence of a specific fuel composition. But whatever the size of the tank, the filling rate and the tank thickness, it turns out that in presence of E10 $\left(P_{H D P E}=65 \mathrm{~g} \cdot \mathrm{mm} /{ }^{2}\right.$.day, $P_{P A 6}=2 \mathrm{~g} \cdot \mathrm{mm} /{ }^{2}$.day, $\left.\varphi_{i}=0.1, d_{i}=0.79, d_{j}=0.78, f_{j}=0.93, f_{i}=0.965\right)$, the fuel exhaustion process of HDPE is 3.5 faster than the fuel exhaustion process of PA6, and this despite the fact that E10 contains much more hydrocarbons than ethanol, which is favorable for HDPE.

\subsection{Influence of the Temperature on PA Permeability to Biofuels}

The influence of temperature on the barrier properties of PA6 to biofuels presenting various ethanol contents was then studied by varying between $30^{\circ} \mathrm{C}$ and $50^{\circ} \mathrm{C}$ the temperature of the FID gas chromatography pervaporation experiment. Figure 17a shows the evolution of the stationary state permeability of $200 \mu \mathrm{m}$ thick PA6 films with the temperature for 4 fuel compositions containing $10 \%$ (E10), 22\% (E22), 85\% (E85) or 100\% (E100) of 

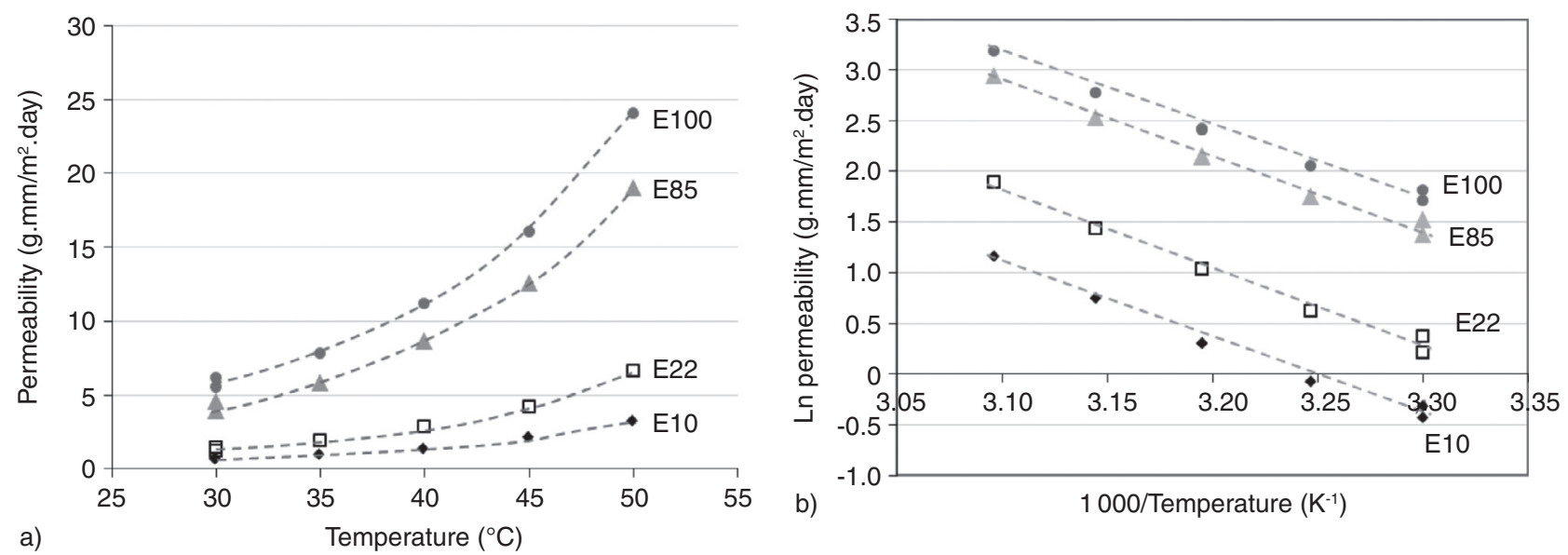

Figure 17

Influence of the temperature on the permeability of PA6 measured by FID gas chromatography for different fuel compositions containing $10,22,85$ or $100 \%$ of ethanol a) plot of temperature as a function of time, b) Logarithm of the permeability as a function of 1000 / temperature.

TABLE 3

Apparent activation energies for the permeation process of different polymers in presence with fuels containing different ethanol contents - PA6: experimental data of the current work, HDPE* and PA12*: data from [1]

\begin{tabular}{l|c|c|c|c|c}
\hline Fuel & E0 & E10 & E22 & E85 & E100 \\
\hline $\mathrm{E}_{a}(\mathrm{~kJ} / \mathrm{mol})-\mathrm{PA6}$ & $\mathrm{x}$ & 61.5 & 64.1 & 60.1 & $\mathrm{x}$ \\
\hline $\mathrm{E}_{a}(\mathrm{~kJ} / \mathrm{mol})-\mathrm{HDPE}^{*}$ & 53.7 & 52.3 & $\mathrm{x}$ & $\mathrm{x}$ & $\mathrm{x}$ \\
\hline $\mathrm{E}_{a}(\mathrm{~kJ} / \mathrm{mol})-\mathrm{PA}^{*}$ & 72.2 & 50 & $\mathrm{x}$ & \\
\hline
\end{tabular}

ethanol. In accordance with the results presented in Section 2, the permeability of PA6 increases as ethanol content increases, and it is also evidenced that permeability increases as temperature increases.

It is well established that fickian diffusion of small-size molecules in polymers is a thermally activated process [25], and a large number of data in the literature suggests that the permeability depends on temperature via an Arrhenius's law defined in Equation (7) [26]:

$$
P(T)=P_{0} \exp \left(\frac{-E_{a}}{R T}\right)
$$

with $P(T)$ the permeability at a temperature $T, P_{0}$ a preexponential factor representing the value of $P$ for an infinite molecular agitation $(T \rightarrow \infty), E_{a}$ the apparent activation energy for the permeation process, $R$ the gas constant equal to $8.314 \mathrm{~J} / \mathrm{mol}$.K, and $T$ the temperature.

The linear evolution of the natural logarithm of the permeability with the inverse of the temperature plotted in Figure 17b suggests that the permeability of PA6 to biofuels follows effectively an Arrhenius law. The activation energies for the different fuels can be deduced from the slopes of the straight lines plotted in Figure 17b, the calculated values being given in Table 3 .

The values of the apparent activation energies for the pervaporation process of PA6 is close to $60 \pm 4 \mathrm{~kJ} / \mathrm{mol}$ and it seems that the ethanol content in the fuel little affects the activation energy values. This value for PA6 is consistent with data from the literature describing the evolution of the permeability with the temperature of various polymers in presence of fuel $\mathrm{C}$ (isooctane/ toluene mixture) or fuels CE10 (equivalent to the E10 denomination in the current work), the data for PA12 and HDPE reported in the paper of Nulman et al. [1] being reported in Table 3 . These results are in agreement with an oft quoted rule of thumb stating that permeability of solvents through polymeric materials decreases (increases) by about $10 \%$ for a $1{ }^{\circ} \mathrm{C}$ decrease (increase) in temperature. 


\section{CONCLUSION}

This article showed that until $85 \%$ of ethanol in the biofuel, the barrier performance of polyamide 6 is much better than that of HDPE, the very slow diffusion kinetics in PA6 in comparison with HDPE being at the origin of the smaller permeability values of PA6. In addition, FID gas chromatography showed that more than $95 \%$ of the solvent flux that permeates through PA6 is composed of ethanol. A direct consequence, which is important to consider from an Health and Safety point of view, is that hydrocarbons content (including toxic aromatics components) is 900 times lower in the solvent flux of PA6 than in that of HDPE in presence of E10. Secondly, as SHED test does not allow any speciation of the solvent molecules, ethanol in this test configuration is counted as a propane molecule, and at the end, this should lead to an under-estimation of the permeability of PA6, little variation being expected for the permeation value of HDPE. A third side effect associated to the solvent flux composition is the fuel exhaustion process, which consists in a decrease of the reduced flux due to the evolution of the fuel in the tank or in the permeation cup, the fuel evolution being itself caused by the preferential diffusion of one of the solvent present in the mixture. This phenomenon should be taken in consideration when assessing the permeability of thin samples, the fuel composition evolution kinetics in thick tanks being a very slow process. But it should be pointed out that in presence of E10, the fuel exhaustion process is 3.5 times faster for HDPE than for PA6. The influence of temperature on PA6 biofuels barrier properties was also studied, and it turned out that the dependence of permeability with temperature varies little with the ethanol content in the fuel, the mean apparent activation energy obtained for PA6 $(60 \mathrm{~kJ} / \mathrm{mol})$ being of the same order of magnitude than the values found in the literature for other polymers such as PA12 or HDPE. Concerning the diffusion processes, it was shown that in the case of PA6, despite a non fickian behavior due to the fact that ethanol strongly increases the molecular mobility of PA6 amorphous phase ("plasticizing" effect), solvents diffusion kinetics evolve with the square of the thickness: indeed, mastercurves were obtained if the solvent uptake (sorption experiment) is plotted as a function of the square root of time divided by the thickness, or if the solvent flux (pervaporation experiment) is plotted as a function of the time divided by the square of the thickness. This allows predicting the permeability of thick parts by extrapolating the value obtained on thin samples. To conclude, it emerges from this work that PA6 based formulations can be suitable for fuel tanks applications, and beyond their interesting intrinsic barrier performance, it should be underlined that in comparison with multi-layer structures, monolayer constructions also offer a greater potential for accurate models and simulation tools. Indeed, from an easily accessible permeability measurement at the lab scale and an accurate knowledge of the fuel tank geometry, it is possible to predict the permeability of the fuel tank in specific conditions similar to the lab scale ones, and on the basis of the data presented in this article (influence of ethanol content, temperature, fuel composition evolution), permeability of parts subjected to various environments could also be accurately extrapolated.

\section{ACKNOWLEDGMENTS}

The work presented here is related to a research program conducted in the LPMA (Solvay-CNRS joint lab) on polymer-solvents interactions and diffusion mechanisms. We acknowledge scientific discussions with Didier Long, Paul Sotta, Agustin Rios de Anda and Erik Lange. The authors are grateful to Duramat project for the financial support. They are also very grateful to Vincent Curtil and Fabrice Chavand from Solvay facilities for the processing of the samples, and to Erwann Jeanneau from the "Centre Henri Longchambon" for the X-Ray diffraction measurements.

\section{REFERENCES}

1 Nulman M., Olejnik A., Samus M., Fead E., Rossi G. (2001) Fuel Permeation Performance of Polymeric Materials, SAE Technical Paper 2001-01-1999.

2 Gagnard C., Germain Y., Keraudren P., Barrière B. (2003) Permeability of Semicrystalline Polymers to Toluene/ Methanol Mixture, Journal of Applied Polymer Science 90, 2727-2733.

3 Berlanga-Labari C., Albistur-Goni A., Barado-Pardo I., Gutierrez-Pinado M., Fernandez-Carrasquilla J. (2011) Compatibility study of high density polyethylene with bioethanol-gasoline blends, Materials and Design 32, 441-446.

4 Gonzalez-Nunez R., Padilla H., De Kee D., Favis B.D. (2001) Barrier properties of polyamide-6/high density polyethylene blends, Polymer Bulletin 46, 323-330.

5 Yeh J.T., Chao C.C., Chen C.H. (2000) Effects of Processing Conditions on the Barrier Properties of Polyethylene (PE)/Modified Polyamide (MPA) and Modified Polyethylene 5MPE)/Polyamide (PA) Blends, Journal of Applied Polymer Science 79, 1997-2008.

6 Subramanian P.M. (1985) Permeability Barriers by Controlled Morphology of Polymer blends, Polymer Engineering and Science 25, 483-487. 
7 Yeh J.T., Fan-Chiang C.C. (1997) The Barrier, Impact, Morphology, and Rheological Properties of Modified Polyamides and their Corresponding PolyethyleneModified Polyamide Blends, Journal of Applied Polymer Science 66, 2517-2527.

8 Yeh J.T., Jyan C.F., Yang S.S., Chou S. (1999) Influence of Compatibilization and Viscosity Ratio on the Barrier and Impact Properties of Blends of a Modified Polyamide-6 and Polyethylene, Polymer Engineering and Science 39, 1952-1961.

9 Yeh J.T., Huang S.S., Yao W.H. (2002) Gasoline Permeation Resistance of Containers of Polyethylene, Polyethylene/ Modified Polyamide and Polyethylene/Blends of Modified Polyamide and Ethylene Vinyl Alcohol, Macromolecular Materials and Engineering 287, 532-538.

10 Yeh J.T., Chen C.H., Shyu W.D. (2001) Gasoline Permeation Resistance of the As-Blow-Molded and Annealed Polyethylene, Polyethylene/Polyamide, and Polyethylene/ Modified Polyamide Bottles, Journal of Applied Polymer Science 81, 2827-2837.

11 Yeh J.T., Fan-Chiang C.C. (1996) Permeation Mechanisms of Xylene in Blow-Molded Bottles of Pure Polyethylene, Polyethylene/Polyamide and Polyethylene/Modified Polyamide Blends, Journal of Polymer Research 3, 211-219.

12 Yeh J.T., Chang S.S., Yao H.T., Chen K.N., Jou W.S. (2000) The permeation resistance of polyethylene, polyethylene/polyamide and polyethylene/modified polyamide blown tubes against unleaded gasoline, Journal of Materials Science 35, 1321-1330.

13 Puffr R., Sebenda J. (1967) On the Structure and Properties of Polyamides. XXVII. The Mechanism of Water Sorption in Polyamides, Journal of Polymer Science: Part C 16, 7993.

14 Murthy N.S., Stamm M., Sibilia J.P., Krimm S. (1989) Structural Changes Accompanying Hydration in Nylon 6, Macromolecules 22, 1261-1267.

15 Nilsson P.G., Lindman B. (1983) Water self-diffusion in nonionic surfactant solutions, hydratation and obstruction effects, Journal of Physical Chemistry 87, 4756-4761.

16 Sabard M., Gouanvé F., Espuche E., Fulchiron R., Seytre G., Fillot L.A., Trouillet-Fonti L. Influence of montmorillonite and film processing conditions on the morphology of polyamide 6: effect on ethanol and toluene barrier properties, accepted in Journal of Membrane Science.
17 Penel-Pierron L., Depecker C., Seguela R., Lefebvre J.M. (2001) Structural and Mechanical Behavior of Nylon 6 Films. Part I. Identification and Stability of the Crystalline Phases, Journal of Polymer Science. Part B: Polymer Physics 39, 484-495.

18 Long F.A., Richman D. (1960) Concentration Gradients for Diffusion of Vapors in Glassy Polymers and their Relationship to Time Dependent Diffusion Phenomena, Journal of American Chemical Society 82, 513-519.

19 Berens A.R., Hopfenberg H.B. (1978) Diffusion and relaxation in glassy polymer powders: 2. Separation of diffusion and relaxation parameters, Polymer 19, 489-496.

20 Hui C.Y., Wu K.C., Lasky R.C., Kramer E.J. (1987) Case-II Diffusion in Polymers. I. Transient Swelling, Journal of Applied Physics 61, 5129-5136.

21 Hui C.Y., Wu K.C., Lasky R.C., Kramer E.J. (1987) Case-II Diffusion in Polymers. II. Steady State Front Motion, Journal of Applied Physics 61, 5137-5149.

22 Rios A., Fillot L.A., Rossi S., Long D., Sotta P. (2011) Influence of the sorption of polar and non-polar solvents on the glass transition temperature of polyamide 6,6 amorphous phase, Polymer Engineering and Science 51, 11, 21292135.

23 Sabard M., Espuche E., Gouanvé F., Fulchiron R., Seytre G., Fillot L.A., Trouillet-Fonti L. (2012) Influence of Film Processing Conditions on the Morphology of Polyamide 6: Consequences on Water and Ethanol Sorption Properties, Journal of Membrane Science 415-416, 670-680.

24 Lange E., Masnada E., Rios A., Fillot L.A., Sotta P., Long D. Solvent diffusion in glassy polymers: a macroscopic approach, (in preparation).

25 Barrer R.M. (1937) Nature of the Diffusion process in Rubber, Nature 140, 106-107.

26 Rogers C.E. (1985) Permeation of Gases and Vapours in Polymers, in Polymer Permeability, Comyn J. (ed.), Elsevier Applied science, pp. 11-73. 